\title{
Ablation of Cardiac Atrioventricular Node
}

National Cancer Institute

\section{Source}

National Cancer Institute. Ablation of Cardiac Atrioventricular Node. NCI Thesaurus.

Code C99908.

An invasive therapeutic procedure to destroy tissue in the AV-node that contributes to an arrhythmia. (ACC) 